\title{
Pentingnya Pengetahuan Tentang Sasaran Keselamatan Pasien Dalam Asuhan Keperawatan
}

\author{
Najla Asyah Syafawani Lubis/191101010
}

najlaasyahsyafawani@gmail.com

\section{Latar Belakang}

Pembangunan kesehatan telah berhasil meningkatkan pelayanan kesehatan secara lebih merata, namun peningkatan mutu baik mutu pelayanan kesehatan itu sendiri maupun mutu sumber daya manusia masih perlu senantiasa diupayakan dengan lebih mengembangkan dan menerapkan ilmu pengetahuan dan teknologi. Dengan semakin meningkatkan pendidikan dan status sosial ekonomi, masyarakat cenderung menuntut pelayanan kesehatan lebih baik dan lebih bermutu.

Rumah Sakit sebagai salah satu institusi pelayanan kesehatan memiliki fungsi penting dalam meningkatkan derajat kesehatan masyarakat sehingga dituntut untuk selalu meningkatkan mutu pelayanan yang diberikan. Dalam hal ini semua pihak di dalam rumah sakit saling berkaitan satu sama lain, mulai dari Yayasan pemilik, direksi, para dokter, perawat, dan profesional lainnya serta staf pada umumnya.

Kualitas rumah sakit tidak hanya terlihat dari bangunan megah, dokter-dokter yang berpengalaman, obat-obatan yang lengkap, dan peralatan medis yang serba canggih. Rumah Sakit dituntut untuk memberikan pelayanan kesehatan terbaik dan lebih terbuka pada masyarakat. Kepercayaan masyarakat terhadap mutu pelayanan kesehatan dapat ditingkatkan dengan adanya status akreditasi karena standar standar yang ditetapkan dalam akreditasi dibuat untuk memenuhi hak-hak pasien.

Berdasarkan UU No. 44 tahun 2009 tentang Rumah Sakit mewajibkan rumah sakit menjalani akreditasi, Peraturan Menteri Kesehatan No. 659 tahun 2009 tentang Rumah Sakit Indonesia kelas Dunia, SK Menteri Kesehatan No. 1195 tahun 2010 tentang Lembaga Akreditasi Rumah Sakit Bertaraf Internasional, dan Keputusan Direktur Jendral Bina Upaya Kesehatan Nomor HK.02.04/1/2 90/11 Tentang Standart Akreditasi Rumah Sakit menunjukkan bahwa pemerintah Tengah melakukan penyempurnaan akreditasi Rumah Sakit menuju akreditasi internasional yaitu 
JCI (Joint Commission International). JCI adalah suatu organisasi yang independen, nonprofit, dan bukan lembaga pemerintahan yang berpusat di Amerika Serikat dan merupakan divisi dari Joint Commission Resources (JCR) cabang dari The Joint Commission. Fokus dan akreditasi JCI adalah keselamatan pasien (Pantient safety yang tertuang dalam standar 6 sasaran keselamatan pasien (Pambudi dkk, 2018).

Sasaran keselamatan pasien (SKP) menjadi indikator standar dasar yang utama dalam penilaian akreditasi Rumah Sakit versi 2012 (KARS, 2013). Ada 6 sasaran keselamatan pasien yaitu ketepatan indikasi pasien, peningkatan komunikasi yang efektif, peningkatan keamanan obat yang perlu diwaspadai, kepastian tepat operasi, tepat prosedur, tepat pasien operasi, pengurangan risiko infeksi terkait pelayanan kesehatan, dan pengurangan resiko pasien jatuh ( Permenkes Nomor 1691, 2011).

Pengetahuan perawat merupakan hal yang berhubungan dengan komitmen membangun budaya keselamatan pasien (Cahyono, 2008). Pengetahuan adalah salah satu faktor dari manusia yang berpengaruh terhadap kejadian nyaris cedera dan kejadian tidak diharapkan. Patient Safety merupakan proses dalam rumah sakit yang memberikan pelayanan pasien yang lebih aman. Termasuk di dalamnya assesmen risiko, identifikasi, dan manajemen risiko terhadap pasien, pelaporan dan analisis insiden, kemampuan untuk belajar dan Menindaklanjuti insiden, dan menerapkan solusi untuk mengurangi serta meminimalisir timbulnya risiko (Ariyani, 2008).

\section{Metode}

Rancangan penugasan kajian ini menggunakan metode literatur review. Dimana metode ini dapat menyelesaikan suatu masalah dengan mengumpulkan data, menganalisa, membandingkan sehingga dapat menentukan pengambilan keputusan dalam masalah tersebut yang berdasarkan dari penjelasan sumber dan referensi yaitu berupa jurnal, ebook atau buku teks.

\section{Hasil}

Berdasarkan hasil penelitian Setiyani dan Syahridal, 2016. Menunjukkan bahwa capaian implementasi sasaran keselamatan pasien sebesar 74,2\% (23 perawat) sudah baik. Sebagian besar perawat sudah baik dalam mengimplementasikan sasaran keselamatan pasien. Hal ini menunjukkan kepedulian perawat terhadap implementasi keselamatan pasien walau hasil yang 
diharapkan implementasi sasaran keselamatan pasien menurut KARS (2013) seharusnya mencapai $100 \%$. Hasil penelitian ini sejalan dengan hasil penelitian yang dilakukan oleh Aruningrum, 2014. Hasil penelitian menunjukkan bahwa pengetahuan responden dalam sasaran keselamatan pasien didapat $97 \%$ responden mengetahui identifikasi pasien, $88 \%$ responden mengetahui tentang komunikasi efektif, 99\% responden mengetahui penggunaan obat, 95\% responden mengetahui tentang pengendalian infeksi, dan $70 \%$ responden mengetahui pengendalian resiko jatuh. Dari Penjelasan diatas dapat disimpulkan bahwa pengetahuan responden tentang patient safety dalam kategori baik paling tinggi presentasinya.

Hasil penelitian Aryani, 2008. Tentang analisis pengetahuan dan motivasi perawat yang mempengaruhi sikap mendukung penerapan program patient safety diinstalasi perawatan intensif RSUD Dr Moewardi Surakarta, didapatkan hasil analisis deskriptif sikap mendukung tinggi (76,3\%), pengetahuan perawat baik $(76,3 \%)$, motivasi perawat baik (71,1\%). Pada hasil penelitian Pambudi dkk, 2018. Sebagian besar $68,5 \%$ responden memiliki pengetahuan yang baik tentang penerapan SKP. Namun di sisi lain masih juga didapatkan perawat memiliki pengetahuan yang kurang sebanyak 31\% sehingga pada penerapan 6 SKP masih ada beberapa poin yang tidak dilaksanakan. Hal ini disebabkan karena minimnya perhatian dan evaluasi tentang penerapan 6 SKP. pelatihan merupakan salah satu cara yang ditempuh untuk meningkatkan pengetahuan.

Pada penelitian Harus dan Sutriningsih, 2015. Hasil yang didapat pengetahuan perawat tentang KPRS di rumah sakit Panti Waluya Sawahan Malang menunjukkan sebagian besar responden $(81,7 \%)$ mempunyai pengetahuan yang cukup. Hasil penelitian yang dilakukan oleh Aprilia, 2011. Dimana didapatkan bahwa pengetahuan perawat tentang sasaran keselamatan pasien paling banyak Pada kategori tinggi sebesar 54,8\% dan pengetahuan terendah sebesar 45,2\%. Hal ini ini mencerminkan bahwa tenaga perawat yang bekerja di rumah sakit masih banyak yang belum mengetahui tentang keselamatan pasien dan juga belum mengetahui Pentingnya menjaga keselamatan pasien pada saat memberikan tindakan baik medis ataupun keperawatan.

\section{Pembahasan}

Rumah Sakit merupakan salah satu tempat yang memberikan pelayanan kesehatan pada pasien, dengan berbagai macam jenis tenaga kesehatan di antaranya adalah perawat dan dokter. Tenaga 
kesehatan yang bekerja di Rumah Sakit bertanggung jawab dalam meningkatkan mutu pelayanan kesehatan dalam pengelolaan manajemen risiko keselamatan pasien di rumah sakit (Kemenkes dan KARS, 2011). Pada saat ini setiap rumah sakit diwajibkan untuk meningkatkan mutu pelayanan kesehatan yang salah satunya adalah melalui sasaran keselamatan pasien. Sasaran keselamatan pasien yang dimaksud dalam akreditasi Rumah Sakit adalah sasaran keselamatan pasien (SSP) yang terdiri dari Sasaran I adalah ketepatan identifikasi pasien, Sasaran II adalah peningkatan komunikasi yang efektif, Sasaran III adalah peningkatan keamanan obat yang perlu diwaspadai, sasaran IV adalah kepastian tepat lokasi, tepat prosedur, dan tepat pasien operasi, Sasaran V adalah pengurangan risiko infeksi terkait pelayanan kesehatan, Sasaran VI adalah pengurangan resiko pasien jatuh ( Direktoran BUN, Kemenkes, dan KARS, 2011).

Sasaran keselamatan pasien terdiri atas 6 Sasaran yaitu:

\section{Ketepatan Identifikasi Pasien}

Rumah Sakit telah berupaya untuk memperbaiki pelaksanaan identifikasi pasien sesuai prosedur. Proses identifikasi pasien dilakukan sejak dari awal pasien masuk rumah sakit dan akan selalu dikonfirmasi dalam segala proses di rumah sakit. Semua pasien baru yang masuk telah diberikan gelang identitas dan ditanyakan namanya saat gelang disematkan, pemberian gelang tersebut untuk memudahkan proses identifikasi pasien. Pada saat pemasangan gelang identitas, pasien akan diberitahu mengenai manfaat gelang dan perawat wajib menjelaskan Resiko yang akan timbul jika tidak dipasang gelang identitas.

\section{Komunikasi Efektif}

Komunikasi efektif merupakan kunci untuk mencapai keselamatan pasien di rumah sakit. KARS (2017) menyatakan capaian komunikasi efektif harus $100 \%$ sehingga dapat disimpulkan bahwa capaian komunikasi efektif belum memenuhi standar KARS 2017. Penelitian Leonard et al (2004) dan Reader et al (2007) menyatakan bahwa komunikasi tampil sebagai penyebab utama yang membahayakan pasien dalam banyak laporan insiden. Menurut Kemkes, (2011) komunikasi yang mudah terjadi kesalahan kebanyakan terjadi pada saat instruksi atau perintah diberikan melalui telepon. Rumah Sakit wajib menerapkan standar keselamatan pasien dan wajib mengupayakan pemenuhan keselamatan pasien. salah satunya adalah peningkatan komunikasi yang efektif. Komunikasi adalah penyebab pertama masalah keselamatan pasien. komunikasi 
yang tepat, akurat, jelas, lengkap, dan dipahami oleh pasien akan mengurangi kesalahan dan menghasilkan peningkatan keselamatan pasien. jenis komunikasi yang dapat dilakukan untuk menunjang pelaksanaan keselamatan pasien menurut Sammer, Lykens, Sigh, Mains, \& Lackan, (2010) diantaranya; Structured techniques (read-back, SBAR). Manojlovich, (2007) menyatakan komunikasi dokter dan perawat mempunyai peran penting dalam menentukan derajat kesehatan pasien, dan kualitas pelayanan yang diberikan. semakin baik komunikasi di antara perawat dan dokter semakin baik hasil perawatan yang diberikan.

\section{Keamanan Obat dan Cairan}

Salah satu tindakan yang mengancam keselamatan pasien adalah kesalahan pemberian obat yang dilakukan oleh perawat. sebagian besar perawat telah menerapkan keamanan obat dan cairan. penerapan 8 benar dengan menunjang keselamatan pasien yaitu: benar pasien, benar obat, benar dosis, benar waktu, benar cara atau route pemberian, benar dokumentasi, benar informasi, dan benar pengkajian juga sudah diterapkan. Menurut Kemenkes (2011), obat-obatan menjadi bagian dari rencana pengobatan pasien, manajemen Rumah Sakit harus berperan secara kritis untuk memastikan keselamatan pasien. Nama obat, rupa dan ucapan mirip (NORUM), yang membingungkan staf pelaksana merupakan salah satu penyebab yang paling sering dalam kesalahan obat atau medical error. oleh karena itu, kewaspadaan terhadap obat-obat yang tingkat bahayanya tinggi harus ditunjukkan dengan menyimpannya di tempat-tempat khusus dan tidak di setiap ruangan. obat-obatan lain harus di bawah pengawasan apoteker, sehingga kalau ada dosis yang berlebihan dapat disarankan ke dokter untuk meninjau kembali terapinya.

\section{Ketepatan Lokasi, Prosedur, Pasien Operasi}

Munurut Kemenkes (2011), Salah lokasi, salah prosedur, salah pasien operasi merupakan sesuatu yang menghawatirkan dan sering terjadi di rumah sakit. kesalahan ini akibat dari komunikasi yang tidak efektif atau tim bedah yang kurang atau tidak melibatkan pasien saat penandaan lokasi. Disamping itu, ada beberapa faktor yang sering terjadi, antara lain: pengkajian pasien yang tidak adekuat, budaya yang tidak mendukung komunikasi antar anggota tim bedah.

\section{Pengurangan Risiko Infeksi}


Rumah Sakit merupakan tempat yang rentan terjadi infeksi nosokomial atau infeksi baru selama perawatan. meski dapat juga terjadi pada pengunjung, infeksi ini paling sering menjangkiti pasien dengan kondisi daya tahan tubuh yang sedang menurun. adanya infeksi baru kadangkadang juga dapat memicu dampak yang lebih fatal saat dirawat di rumah sakit terutama saat berada di ruangan bedah. infeksi yang terjadi pada pelayanan kesehatan selama masa perawatan merupakan hal yang harus dibatasi penyebarannya dan tindakan pengurangan terhadap risiko infeksi dilaksanakan hand hygiene sesuai aturan adalah cara yang paling efektif untuk dilakukan (KARS, 2017).

\section{Pengurangan Risiko Jatuh}

jumlah kasus jatuh cukup bermakna sebagai penyebab cidera bagi pasien rawat inap. mengingat risiko pasien jatuh sangat besar Maka sebagai perawat perlu memikirkan berbagai cara untuk mengurangi terjadinya hal tersebut. Hal ini dilakukan dengan tujuan pasien tidak perlu dirawat di rumah sakit lebih lama akibat komplikasi jatuh. menurut Potter dan Perry (2009) beberapa intervensi yang dapat dilakukan perawat untuk mencegah terjadinya jatuh pada pasien antara lain: mengorientasikan pasien pada saat masuk rumah sakit dan menjelaskan sistem komunikasi yang ada, bersikap hati-hati saat mengkaji pasien dengan keterbatasan gerak, melakukan supervisi ketat pada awal pasien dirawat terutama malam hari, menganjurkan menggunakan bel bila membutuhkan bantuan, memberikan alas kaki yang tidak licin, memberikan pencahayaan yang adekuat, memasang pengaman tempat tidur terutama pada pasien dengan penurunan kesadaran dan gangguan mobilitas, dan menjaga lantai kamar mandi agar tidak licin.

Berdasarkan uraian tersebut, untuk dapat membudayakan keselamatan pasien maka langkah awal yang perlu diperhatikan kan oleh tenaga kesehatan/Perawat yaitu pengetahuan. Langkah awal tersebut adalah dimulai dari mengetahui pengetahuan tenaga kesehatan yang dimiliki dalam mengaplikasikan keselamatan pasien. pengetahuan merupakan domain yang sangat penting untuk terbentuknya tindakan seseorang. pengetahuan diperlukan sebagai dukungan dalam menumbuhkan rasa percaya diri maupun sikap dan perilaku, sehingga pengetahuan merupakan Fakta yang mendukung tindakan seseorang. Menurut Myers, (2012) mengatakan bahwa penerapan patient safety sangat tergantung dari pengetahuan petugas kesehatan. apabila petugas menetapkan patient safety didasari oleh pengetahuan yang memadai, maka penerapan patient safety oleh petugas tersebut akan bersifat langgeng (long lasting). 
Menurut Bawelle, Silonungan dan Hamel (2013), menyatakan bahwa pengetahuan merupakan faktor penting dalam seseorang mengambil keputusan namun tidak selamanya pengetahuan seseorang bisa menghindarkan dirinya dari kesalahan, misalnya petugas kesehatan yang tingkat pengetahuannya baik tidak selamanya melaksanakan keselamatan pasien dengan baik karena segala tindakan yang akan dilakukan beresiko untuk terjadi kesalahan dalam pelaksanaan sasaran keselamatan pasien. pengetahuan seseorang tentang suatu objek mengandung 2 aspek, yaitu aspek positif dan negatif. kedua aspek ini akan menentukan sikap seseorang semakin banyak aspek positif dan objek yang diketahui, maka akan menimbulkan sikap makin positif terhadap objek tertentu (Wawar dan Dewi, 2011).

Pengetahuan perawat tentang patient safety merupakan hal penting, karena jika pengetahuan perawat tentang pantient safety kurang maka jelas ini akan berpengaruh terhadap kinerja perawat itu sendiri dalam penerapan patient safety di rumah sakit (Notoatmojo,2012). Dalam kode etik keperawatan disebutkan bahwa perawat memiliki tanggung jawab agar senantiasa memelihara mutu pelayanan keperawatan yang tinggi disertai kejujuran profesional yang menerapkan pengetahuan serta keterampilan keperawatan sesuai dengan kebutuhan klien. dalam hubungannya dengan teman sejawat, perawat berkewajiban melindungi klien dari tenaga kesehatan yang memberikan pelayanan kesehatan secara tidak kompeten, tidak etis dan ilegal (Cahyono, 2015). Oleh karena itu, sangat penting pengetahuan pada perawat tentang penerapan sasaran keselamatan pasien dalam asuhan keperawatan.

\section{Kesimpulan}

Berdasarkan data-data hasil penelitian dapat disimpulkan bahwa beberapa tenaga kesehatan seperti perawat memiliki pengetahuan yang kurang baik tentang sasaran keselamatan pasien di rumah sakit, yang menunjukkan bahwa identifikasi pasien, komunikasi efektif, keamanan obat, kepastian tepat lokasi, prosedur, pasien operasi, pengendalian infeksi, pencegahan pasien jatuh belum dipahami/ kurangnya pengetahuan oleh tenaga kesehatan yaitu seperti perawat.

Terdapat hubungan penting antara tingkat pengetahuan perawat dan praktik keselamatan pasien, diketahui pula bahwa semakin tinggi tingkat pengetahuan perawat tentang keselamatan pasien maka praktek keselamatan pasien dalam asuhan keperawatan semakin baik dan benar. Diharapkan bagi Rumah Sakit dapat mengadakan seminar dan pelatihan secara berkala tentang 
sasaran keselamatan pasien dan melakukan pengawasan secara optimal bagi perawat dan dokter untuk meningkatkan kualitas pelayanan kesehatan.

\section{Daftar Pustaka}

Arruum, D., Salbiah., \& Manik, M. (2015). Pengetahuan Tenaga Kesehatan Dalam Sasaran Keselamatan Pasien Di Rumah Sakit Sumatera Utara. Idea Nursing Journal, 6 (2), 1-6.

Cahyono, A. (2015). Hubungan Karakteristik Dan Tingkat Pengetahuan Perawat Terhadap Pengelolaan Keselamatan Pasien Di Rumah Sakit. Jurnal Ilmiah WIDYA, 3 (2), 97-102.

Harus, B, D., \& Sutriningsih, A. (2015). Pengetahuan Perawat Tentang Keselamatan Pasien Dengan Pelaksaan Prosedur Keselamtan Pasien Rumah Sakit (KPRS) Dirumah Sakit Panti Waluya Sawahan Malang. Jurnal CARE, 3 (1), 25-32.

Iriviranty, A. (2015). Analisis Budaya Organisasi dan Budaya Keselamtan Pasien sebagai Langkah Pengembangan Keselamatan Pasien di RSIA Budi Kemuliaan. Jurnal Adminstasi Rumah Sakit, 1 (3), 196-203.

Pambudi, Y, D, W., Sutriningsih, A., \& Yasin, D, D, F. (2018). Faktor-Faktor Yang Mempengaruhi Perawat Dalam Penerapan 6 SKP (Sasaran Keselamatan Pasien) Pada Akreditasi JCI (Joint Commision International) Di Ruang Rawat Inap Rumah Sakit Panti Waluya Malang. Nursing News, 3 (1), 729-747.

Sakinah, S., Wigati, P, A., \& Arso, S, P. (2017). Analisis Sasaran Keselamatan Dilihat dari Aspek Pelaksanaan Identifikasi Pasien Dan Keamanan Obat Di RS Kepresidenan RSPAD Gatot Subroto Jakarta. Jurnal Kesehatan Masyarakat, 5 (4), 145-152.

Safitri, W., \& Ati, A, M. (2018). Tingkat Pengetahuan dengan Sikap Dan Praktik Perawat Dalam Implementasi Patient Safety: Risiko Jatuh Di RSUD Dr. Soehadi Briedjonegoro Sragen. Adi Husada Nursing Journal, 4 (1), 28-32.

Siregar, R, A. (2016). Hubungan Perawat Dan Pasien: Implementasi Standar Keselamatan Pasien. Jurnal Hukum to-ra, 2 (1), 295-304. 
Simamora, R. H. (2018). Buku ajar keselamatan pasien melalui timbang terima pasien berbasis komunikasi efektif: SBAR. Medan: USUpress.

Simamora, R. H. (2020). Learning of Patient Identification in Patient Safety Programs Through Clinical Preceptor Models. Medico Legal Update, 20(3), 553-556.

Sundoro, T., Rosa, E, M., \& Risdiana, I. (2016). Evaluasi Pelaksaan Sasaran Keselamatan Pasien Sesuai Akreditasi Rumah Sakit Versi 2012 Di rumah sakit khusus Ibu Dan Anak PKU Muhammadiyah Kotagede Yogyakarta. Jurnal Mediocoeticolegal dan Menejemen Rumah Sakit, $5(1), 40-48$.

Sriningsih, N., \& Marlina, E. (2020). Pengetahuan Penerapan Keselamatan Pasien (Patien Safety) Pada Petugas Kesehatan. Jurnal Kesehatan, 9 (1). 